\title{
IKLIM KERJA DAN STATUS GIZI DENGAN KELELAHAN KERJA PADA PEKERJA DI BALLAST TANK BAGIAN REPARASI KAPAL PT. X SURABAYA
}

\author{
Yuli Suryaningtyas*, Noeroel Widajati* \\ Departemen Keselamatan dan Kesehatan Kerja \\ *Fakultas Kesehatan Masyarakat \\ Universitas Airlangga \\ Email: julistyas@gmail.com
}

\begin{abstract}
ABSTRAK
Kelelahan merupakan kejadian yang umum terjadi ketika seseorang bekerja. Kelelahan kerja dapat mengakibatkan penurunan produktivitas dan meningkatkan terjadinya kecelakaan kerja. Faktor penyebab kelelahan kerja diantaranya adalah iklim kerja dan status gizi. Tujuan dari penelitian ini adalah untuk menganalisis hubungan iklim kerja dan status gizi dengan kelelahan kerja pada pekerja di ballast tank bagian reparasi kapal PT. X Surabaya. Penelitian ini merupakan penelitian observasional deskriptif dengan desain penelitian cross sectional. Sampel penelitian merupakan total dari seluruh populasi, yaitu pekerja di ballast tank bagian reparasi kapal yang berjumlah 21 orang. Variabel independen penelitian adalah iklim kerjadan status gizi. Variabel dependen pada penelitian ini adalah kelelahan kerja. Pengukuran kelelahan kerja menggunakan KAUPK2 (Kuesioner Alat Ukur Perasaan Kelelahan Kerja). Analisis data menggunakan uji korelasi pearson dan uji regresi linier berganda. Hasil penelitian menunjukkan bahwa seluruh responden berjenis kelamin laki-laki, sebagian besar responden berumur 36-50 tahun (61,90\%), memiliki masa kerja 1625 tahun (71,40\%) dengan tingkat pendidikan SMA/SMK (95,24\%). Sebagian besar responden memiliki status gizi kategori normal $(52,40 \%)$ dan kelelahan kerja kategori sangat lelah (42,90\%). Iklim kerja di ballast tank menunjukkan hasil >NAB. Hubungan iklim kerja dengan kelelahan kerja memiliki koefisien korelasi sebesar 0,461. Hubungan status gizi dengan kelelahan kerja memiliki koefisien korelasi sebesar 0,592. Berdasarkan hasil uji determinasi diketahui bahwa iklim kerja dan status gizi berpengaruh terhadap kelelahan kerja sebesar 0,381 dan faktor yang paling mempengaruhi kelelahan kerja adalah iklim kerja. Kesimpulan dari penelitian ini adalah iklim kerja dan kelelahan kerja memiliki hubungan yang sedang, serta status gizi dan kelelahan kerja memiliki hubungan yang sedang. Faktor yang paling berpengaruh terhadap kelelahan kerja adalah iklim kerja. Disarankan bagi perusahaan untuk memasang blower pada saat pekerja melakukan aktivitas di ballast tank, pemantauan status gizi, mengadakan program olahraga dan penyediaan air minum.
\end{abstract}

Kata kunci : Iklim Kerja, Status Gizi, Kelelahan Kerja, Tenaga Kerja

\section{ABSTRACT}

The fatigue is common occurence which happens when someone is working. The work fatigue can caused the decline of productivity and increase the occurrence of work accident. The causal factors of work fatigue are work climate and the nutritional status. The purpose of this research is to analyze the relations of work climate and the nutritional status with the work fatigue by the workers in the ballast tank of ship reparation department PT.X Surabaya. This research is observational descriptive with cross sectional design. The sample of this research is the total of entire population, which is the workers in the ballast tank of 
ship reparation department, which amounted to 21 peoples. The independent variable of this research is work climate and nutrition status. The dependent variable of this research is work fatigue. The measurement of work fatigue is using KAUPK2 (Kuesioner Alat Ukur Perasaan Kelelahan Kerja). Analysis of the data is using the pearson corellation test and the multiple linear regression test. The results of this research shows that all respondents are male, majority of respondents are 36-50 years old (61,90\%), who have 16-25 years working period (71,40\%), with senior high schools as the educational level $(95,24 \%)$. The majority of respondents have normal category of nutritional status ( 52,40\%) and very tired category of work fatigue (42.90\%). The work climate in the ballast tank shows result of $>N A B$. The results of the correlation test shows that there wre correlation between work climate and work fatigue has a correlation coefficient of 0, 461. The correlation between nutritional status and work fatigue has a correlation coefficient of 0, 592. Based on the test result had been known that the work climate and nutritional status affected work fatigue with correlation coefficient 0,381 and the factor which most affecting work fatigue is the work climate. The conclusion of this research is there is medium relationship between work climate and work fatigue, as well there is medium relationship between nutritional status and work fatigue. The factor that most influential to work fatigue is work climate. There are an advised for the industry such as install the blower when workers do activities in the ballast tank, do the monitoring of nutritional status, held a sport (gymnastic) program and provision of drinking water.

Keywords : Work Climate, Nutritional Status, Work Fatigue, Worker

\section{PENDAHULUAN}

Perkembangan sektor industri saat ini tidak bisa lepas dari peran seorang tenaga kerja meskipun banyak perusahaan yang menggunakan mesin dan teknologi canggih dalam proses produksinya. Salah satu konsekuensi dari perkembangan industri yang sangat pesat dan persaingan yang ketat antar perusahaan di Indonesia saat ini adalah tertantangnya proses produksi kerja dalam perusahaan agar terus menerus berproduksi selama 24 jam dan diharapkan ada peningkatan kualitas serta kuantitas produksi untuk mencapai keuntungan yang maksimal (Adi, 2013). Hal tersebut mendorong manusia mengerahkan segenap potensi untuk mengembangkan diri dan memanfaatkan fasilitas serta sumber daya yang ada, sehingga dapat mencukupi kebutuhan hidupnya (Susetyo, 2012).

Dalam Undang-undang No. 13 tahun 2003 tentang ketenagakerjaan dalam pasal 86 dijelaskan tenaga kerja berhak mendapat perlindungan atas keselamatan dan kesehatan kerja, pemeliharaan moral kerja dan kesusilaan serta perlakuan yang sesuai dengan harkat dan martabat manusia serta nilai-nilai agama. Salah satu upaya keselamatan dan kesehatan kerja (K3) adalah memelihara faktor-faktor lingkungan kerja agar senantiasa dalam batas-batas yang aman dan sehat. Hal tersebut dimaksudkan agar tidak terjadi 
penyakit atau kecelakaan akibat kerja dan tenaga kerja dapat menikmati derajat kesehatan yang setinggi-tingginya.

Kelelahan merupakan kejadian yang umum terjadi jika seseorang bekerja. Kelelahan merupakan suatu mekanisme yang dimiliki oleh tubuh untuk memberikan peringatan bahwa terjadi sesuatu hal yang mengganggu tubuh dan dapat pulih setelah dilakukan istirahat (Tarwaka, 2010). Istilah kelelahan menunjukan kondisi yang berbeda-beda dari setiap individu. Kelelahan menjadi indikator terjadinya gangguan kesehatan yang dialami tenaga kerja selama melakukan pekerjaan. Penelitian yang dilakukan oleh Setyawati (2013) menyimpulkan bahwa di PT.X Surabaya sebanyak $78,57 \%$ tenaga kerja mengalami kelelahan akut dan sebanyak 59,52\% mengalami kelelahan kronis. Setyawati (2010) memaparkan bahwa lebih dari 60\% pekerja yang datang berobat ke poliklinik perusahaan mengeluh adanya perasaan kelelahan kerja dan perasaan kelelahan kerja merupakan gejala urutan tersering ketujuh yang diketemukan pada suatu studi epidemiologi di USA. Kelelahan dapat mempengaruhi kesehatan pekerja dan dapat pula menurunkan produktivitas.

Faktor penyebab terjadinya kelelahan di industri menurut Setyawati (2010) sangat bervariasi yang dipengaruhi oleh beban kerja, lingkungan kerja, problem fisik, dan kondisi kesehatan. Kelelahan dapat pula dipengaruhi oleh faktor individu seperti: umur, status kesehatan, status gizi, pola makan, jenis kelamin dan kondisi psikologi. Risiko yang dapat ditimbulkan akibat kelelahan diantaranya penurunan motivasi kerja, performansi rendah, rendahnya kualitas kerja, banyak terjadi kesalahan dalam bekerja, rendahnya produktivitas kerja, menyebabkan stres kerja, penyakit akibat kerja, cedera, dan terjadi kecelakaan akibat kerja (Chesnal, 2014).

Iklim kerja merupakan salah satu faktor lingkungan kerja yang berpotensi menimbulkan bahaya yang dapat menimbulkan gangguan kesehatan terhadap tenaga kerja bila berada pada kondisi yang ekstrim panas dan dingin dengan kadar melebihi NAB yang diperkenankan menurut standar kesehatan (Tarwaka, 2008). Setyaningsih (2002) menerangkan bahwa lingkungan kerja sangat berpengaruh terhadap efisiensi dan produktivitas kerja. Permenakertrans Nomor 13 Tahun 2011 menjelaskan iklim kerja adalah perpaduan antara suhu, kelembaban, kecepatan aliran udara dan panas radiasi dengan tingkat pengeluaran panas yang dikeluarkan oleh tenaga kerja sebagai akibat dari pekerjaannya. Bekerja pada lingkungan kerja bersuhu tinggi dapat membahayakan keselamatan dan kesehatan tenaga kerja sehingga untuk bekerja pada 
lingkungan dengan keadaan temperature demikian perlu upaya penyesuaian.

Hasil pengukuran iklim kerja yang dilakukan oleh Priyono (2010) di proyek relokasi jalan arteri raya Porong-Siring 1 Paket 3 Sidoarjo, nilai ISBB di 3 unit kerja didapatkan hasil yang melebihi NAB (Nilai Ambang Batas), yaitu sebesar $25,9^{\circ} \mathrm{C}$ berdasarkan kategori beban kerja berat. Hasil penlitian Ramayanti (2015) diketahui bahwa ada hubungan yang bermakna antara iklim kerja dan kelelahan kerja, yaitu pada kondisi iklim kerja melebihi NAB pada kategori beban kerja yang telah ditentukan terdapat $57,1 \%$ yang mengalami kelelahan kerja kategori tinggi.

Hasil identifikasi Bakhtiar (2011) menjelaskan bahwasannya kondisi di dalam ballast tank atau tangki balas sangat panas karena ruangan tangki yang sangat sempit dan terdapat pekerjaan hot work. Debu dan ventilasi yang kurang di dalam tangki juga membuat lingkungan kerja panas dan kering. Soeripto (2008) mengungkapkan bahwa tekanan panas yang akan diterima oleh tenaga kerja yang bekerja di lingkunga dengan tekanan panas tinggi dapat mengakibatkan gangguan pekerjaan diantaranya kepala pusing, berkeringat, dan cepat lelah. Nurmianto (2004) menyebutkan kondisi panas sekeliling yang berlebihan akan mengakibatkan rasa letih dan kantuk.
Faktor lain yang mempengaruhi kelelahan adalah faktor individu, salah satunya yaitu status gizi. Status gizi merupakan keadaan tubuh sebagai akibat dari konsumsi makanan dan zat gizi. Orang yang sedang berada pada kondisi gizi yang kurang baik akan lebih mudah mengalami kelelahan dalam melakukan pekerjaannya (Oentoro, 2004). Menurut hasil penelitian Ardhani (2011) disebutkan adanya hubungan yang bermakna antara status gizi dengan tingkat kelelahan kerja subjektif pada tenaga kerja di bagian pengepakan di PT. Indofood Sukses Makmur Tbk. Bogasari Mills Surabaya. Dari 47 responden, 53,2\% menunjukkan status gizi gemuk dan sebanyak $76,0 \%$ dari pekerja yang berstatus gizi gemuk tersebut mengalami tingkat kelelahan sedang.

Berdasarkan uraian yang telah dipaparkan maka peneliti tertarik untuk melakukan penelitian mengenai hubungan antara iklim kerja dan status gizi dengan kelelahan kerja pada tenaga kerja di ballast tank bagian reparasi kapal PT. X Surabaya.

\section{METODE}

Penelitian ini merupakan penelitian deskriptif yang bertujuan untuk menjawab rumusan masalah dan mendeskripsikanya. Analisis data yang digunakan adalah uji korelasi untuk mengetahui kuat hubungan antar variabel serta uji regresi untuk mencari hubungan bersama antara variabel 
independen dan dependen. Ditinjau dari waktu penlitian termasuk dalam penelitian cross sectional dimana variabel indpenden dan variabel dependen pada obyek penelitian diukur dan dikumpulkan pada saat yang sama. Berdasarkan pengambilan data termasuk dalam penelitian observasional dimana peneliti hanya melakukan pengamatan tanpa memberikan perlakuan saat di lapangan.

Populasi adalah keseluruhan inividu yang menjadi acuan hasil-hasil penelitian akan berlaku (Lemenshow dkk, 1997). Pada penelitian ini populasi adalah seluruh pekerja di ballast tank bagian reparasi kapal PT. X Surabaya sebanyak 21 orang. Sampel penelitian merupakan total dari seluruh populasi sebanyak 21 orang.

Variabel dapat diartikan sebagai segala sesuatu penggambaran atau abstraksi dari fenomena tertentu yang bervariasi. Variabel independen dalam penelitian ini adalah iklim kerja dan status gizi. Variabel dependen dari penelitian ini adalah kelelahan kerja.

Penelitian dilaksanakan pada bulan April-Juni 2016. Lokasi penelitian dilaksanakan di ballast tank kapal bagian reparasi kapal PT. X Surabaya. Lokasi pengukuran berat badan dan tinggi badan serta pengisian kuesioner menyesuaikan dengan keadaan pada saat penelitian.

Data primer diperoleh melalui hasil pengisian kuesioner, pengukuran antropometri pada responden, pengukuran iklim kerja di ballast tank, dan pengukuran beban kerja. Data sekunder diperoleh dari data perusahaan meliputi gambaran umum perusahaan, profil perusahaan, data kecelakaan kerja, jumlah pekerja, dan lain sebagainya.

Instrumen yang digunakan dalam pengumpulan data adalah kuesioner identitas dan KAUPK2 (Kuesioner Alat Ukur Perasaan Kelelahan Kerja), timbangan berat badan, microtoise stature meter, Heat Stress Apparatus (Quest Temp 36), dan Calorimeter Heart Rate Watch.

Data yang diperoleh selanjutnya akan diolah. Teknik analisis data yang digunakan, yaitu: (a) Analsis univariat, dilakukan pada masing-masing variabel yang akan menghasilkan distribusi dan persentase dari setiap variabel; (b) Analisis bivariat, digunakan untuk mengetahui kuat hubungan dua variabel. Hubungan yang pertama adalah iklim kerja dan kelelahan kerja. Hubungan kedua adalah status gizi dengan kelelahan kerja. Uji yang digunakan adalah uji korelasi Pearson; (c) Analisis multivariat untuk mengetahui hubungan bersama antara variabel dependen dan variabel independen. Uji yang digunakan adalah uji regresi linier. 


\section{HASIL}

\section{Distribusi Frekuensi Karakteristik Responden}

Subjek pada penelitian ini adalah 21 orang pekerja yang bekerja di ballast tank kapal pada bagian reparasi kapal PT. $\mathrm{X}$ Surabaya. Karakteristik yang diidentifikasi meliputi umur, masa kerja, dan tingkat pendidikan. Jenis kelamin untuk pekerja adalah laki-lai, untuk itu tidak perlu diteliti lagi. Hasil dari karakteristik ini diperoleh dari data primer yang dilakukan oleh peneliti. Distribusi frekuensi hasil penlitian karakteristik individu dapat dilihat pada tabel 1 di bawah ini.

Tabel 1. Distribusi Frekuensi Karakteristik Responden di Ballast Tank Bagian Reparasi Kapal PT. X Surabaya.

\begin{tabular}{clcc}
\hline $\begin{array}{c}\text { Karaktristik } \\
\text { responden }\end{array}$ & Kategori & N & $\begin{array}{c}\text { Persen- } \\
\text { tase(\%) }\end{array}$ \\
\hline \multirow{4}{*}{ Umur } & $<35$ tahun & 4 & 19,00 \\
& $36-50$ tahun & 13 & 61,90 \\
& $>50$ tahun & 4 & 19,05 \\
& Total & $\mathbf{2 1}$ & $\mathbf{1 0 0}$ \\
\hline \multirow{5}{*}{ Masa Kerja } & $<5$ tahun & 4 & 19,05 \\
& 6-15 tahun & 0 & 0 \\
& 16-25 tahun & 15 & 71,40 \\
& $>25$ tahun & 2 & 9,55 \\
& Total & $\mathbf{2 1}$ & $\mathbf{1 0 0}$ \\
\hline \multirow{5}{*}{ Tingkat } & SD & 0 & 0 \\
Pendidikan & SMP & 0 & 0 \\
& SMA/SMK & 20 & 95,24 \\
& Perguruan & 1 & 4,76 \\
& Tinggi & $\mathbf{2 1}$ & $\mathbf{1 0 0}$ \\
\hline
\end{tabular}

Berdasarkan hasil penelitian dengan metode kuesioner dapat diketahui sebaran umur dari 21 tenaga kerja yang bekerja di bagian ballast tank. Umur tenaga kerja dikelompokkan berdasarkan 3 kategori yaitu $<35$ tahun, 36-50 tahun, dan $>50$ tahun. Sebaran umur terbanyak berkisar antara 36-50 tahun sebanyak 13 $(61,5 \%)$ orang. Seluruh pekerja di ballast tank berjenis kelamin laki-laki. Hal ini dikarenakan pekerjaan yang dilakukan tergolong kasar dan berat, maka dari itu untuk rekrutmen diutamakan pekerja lakilaki.

Masa kerja tenaga kerja dikelompokkan berdasarkan 4 kategori yaitu $<5$ tahun, 6-15 tahun, 16-25 tahun, dan $>25$ tahun. Paling banyak tenaga kerja bekerja selama 16-25 tahun sebanyak 15 $(71,40 \%)$ orang. Tingkat pendidikan tenaga kerja dikategorikan berdasarkan jenjang pendidikan formal. Hasil yang didapat menunjukkan bahwa 20 (95,20\%) tenaga kerja meiliki pendidikan terakhir SMA/SMK.

\section{Kelelahan Kerja Responden}

Kelelahan kerja yang dialami oleh pekerja di ballast tank dikelompokkan menjadi 3 kategori, yaitu kurang lelah skor $<20$ ), lelah (skor 20-38), dan sangat lelah (skor $>38$ ). Distribusi paling banyak adalah $9(42,90 \%)$ pekerja merasa sangat lelah. Sebanyak 8 orang dengan persentase $38,10 \%$ dari total tenaga kerja merasakan kurang lelah dan sebanyak $4(19,00 \%)$ pekerja merasakan lelah. Lebih sederhananya bisa dilihat pada tabel $2 \mathrm{di}$ bawah ini. 
Tabel 2. Distribusi Frekuensi Kelelahan Kerja Responden

\begin{tabular}{lcc}
\hline $\begin{array}{l}\text { Kelelahan } \\
\text { Kerja }\end{array}$ & $\begin{array}{c}\text { Frek } \\
\text { (Orang) }\end{array}$ & Persentase \\
\hline Kurang lelah & 8 & $38,10 \%$ \\
Lelah & 4 & $19,00 \%$ \\
Sangat lelah & 9 & $42,90 \%$ \\
$\quad$ Total & 21 & $100 \%$ \\
\hline
\end{tabular}

\section{Hubungan Iklim Kerja dengan Kelelahan Kerja}

Hasil pengukuran iklim kerja yang

mengacu pada ISBB yang dilakukan di ballast tank kapal, nilai ISBB paling tinggi adalah $34,83^{\circ} \mathrm{C}$ dan nilai ISBB terendah adalah $33,36{ }^{\circ} \mathrm{C}$. Jika dilihat dari beban kerja yang dimiliki oleh pekerja dan dengan pengaturan jam kerja 50-75\%, iklim kerja di tangki balas kapal tersebut melebihi NAB (Nilai Ambang Batas) iklim kerja yaitu sebesar $31^{\circ} \mathrm{C}$ untuk beban kerja ringan, $29,0^{\circ} \mathrm{C}$ untuk beban kerja sedang, dan $27,5^{\circ} \mathrm{C}$ untuk beban kerja berat.

Iklim kerja yang di ballast tank bagian reparasi kapal menunjukkan hasil $>$ NAB dan keseluruhan dari pekerja mengalami kelelahan yang bervariasi. Sebanyak $8(38,10 \%)$ pekerja mengalami kelelahahan dengan kategori kurang lelah, $4(19,00 \%)$ pekerja mengalami kelelahan kategori lelah, dan $9(42,90 \%)$ pekerja merasakan sangat lelah. Paling banyak dialami yaitu pekerja merasakan sangat lelah pada area kerja dengan iklim kerja $>\mathrm{NAB}$.
Analisis bivariat menggunakan uji statistik korelasi Pearson dapat dilihat pada tabel 3 .

Tabel 3. Hasil Uji Korelasi Iklim Kerja dengan Kelelahan Kerja

\begin{tabular}{|c|c|c|c|}
\hline & & $\begin{array}{l}\text { Iklim } \\
\text { Kerja }\end{array}$ & $\begin{array}{c}\text { Kelelahan } \\
\text { Kerja }\end{array}$ \\
\hline & Person & & \\
\hline \multirow{3}{*}{ Kerja } & Correlation & 1 & $.461^{\prime}$ \\
\hline & $\begin{array}{l}\text { Sig. } \\
\text { tailed) }\end{array}$ & & .035 \\
\hline & $\mathrm{N}$ & 21 & 21 \\
\hline \multirow{4}{*}{$\begin{array}{l}\text { Kelelahan } \\
\text { Kerja }\end{array}$} & Person & & \\
\hline & Correlation & $.461^{\prime}$ & 1 \\
\hline & $\begin{array}{l}\text { Sig. } \\
\text { tailed) }\end{array}$ & .035 & \\
\hline & $\mathrm{N}$ & 21 & 21 \\
\hline
\end{tabular}

Hasil uji korelasi antara variabel independen dan variabel dependen menunjukkan nilai koefisien korelasi yang dihasilkan adalah sebesar 0,461 . Nilai ini menunjukkan hubungan antara variabel iklim kerja dengan kelelahan kerja adalah sedangt dengan arah hubungan positif.

\section{Hubungan Status Gizi dengan Kelelahan Kerja}

Status gizi pekerja diperoleh dari hasil perhitungan IMT (Indeks Masa Tubuh). Status gizi dalam penelitian ini dikategorikan menjadi 3 yaitu kategori kurus, normal, dan gemuk. Kategori kurus jika nilai $\mathrm{IMT} \leq 18,5$, kategori normal jika nilai IMT $>18,5-25$, dan kategori gemuk dengan nilai IMT $>25$. Distribusi terbanyak status gizi pekerja adalah normal, yaitu 11 tenaga kerja dengan persentase $52,4 \%$ dari total tenaga kerja. Sebanyak $38,10 \%$ dari total tenaga kerja yaitu 8 pekerja mempunyai status gizi 
gemuk dan $2(9,50 \%)$ orang memiliki status gizi kurus.

Tabel 4. Distribusi Frekuensi Status Gizi Responden

\begin{tabular}{lcc}
\hline Status Gizi & $\begin{array}{c}\text { N } \\
\text { (Orang) }\end{array}$ & Persentase \\
\hline Kurus & 2 & $9,50 \%$ \\
Normal & 11 & $52,40 \%$ \\
Gemuk & 8 & $38,10 \%$ \\
Total & $\mathbf{2 1}$ & $\mathbf{1 0 0 \%}$ \\
\hline
\end{tabular}

Hasil tabulasi silang antara status gizi dengan kelelahan kerja, dimana kelelahan kerja sendiri dikategorikan menjadi 3 kategori diperoleh hasil 6 $(28,30 \%)$ pekerja yang memiliki status gizi gemuk merasakan sangat lelah. Selain itu 7 $(33,30 \%)$ pekerja merasa kurang lelah dengan status gizi normal. Perasaan sangat lelah juga dirasakan oleh semua pekerja dengan status gizi kurus. Terdapat kecenderungan bahwa semakin buruk (kurus atau gemuk) status gizi seseorang, semakin tinggi kelelahan yang dirasakan.

Analisis bivariat dilakukan untuk mengetahui koefisien korelasi antara status gizi dengan kelelahan kerja. Uji yang digunakan adalah uji statistik korelasi Pearson. Hasilnya dapat dilihat pada tabel 5 berikut ini.

Tabel 5. Hasil Uji Korelasi Status Gizi dengan Kelelahan Kerja

\begin{tabular}{llrr}
\hline & & $\begin{array}{c}\text { Status } \\
\text { Gizi }\end{array}$ & \multicolumn{1}{c}{$\begin{array}{c}\text { Kelelahan } \\
\text { Kerja }\end{array}$} \\
\hline Status & Person & & \\
Gizi & Correlation & 1 & .341 \\
& Sig. (2- & & \\
& tailed) & & .0131 \\
& $\mathrm{~N}$ & 21 & 21 \\
\hline Kelelahan & Person & .341 & 1 \\
\hline
\end{tabular}

\begin{tabular}{llrr}
\hline & & $\begin{array}{c}\text { Status } \\
\text { Gizi }\end{array}$ & $\begin{array}{c}\text { Kelelahan } \\
\text { Kerja }\end{array}$ \\
\hline Kerja & Correlation & & \\
& Sig. $\quad(2-$ & & \\
& tailed) & .131 & \\
N & 21 & 21 \\
\hline
\end{tabular}

Dari hasil analisis korelasi diperoleh kofisien korelasi sebesar 0,341. Nilai ini menunjukkan bahwa terjadi hubungan yang lemah antara status gizi dengan kelelahan kerja. Arah hubungan yang didapat dalah positif.

\section{Hubungan Iklim Kerja dan Status gizi dengan Kelelahan Kerja}

Analisis multivariat dilakukan untuk mengetahui hubungan seluruh variabel independen dengan variabel. Uji yang digunakan adalah uji regresi linier.Uji ini digunakan untuk menilai asosiasi secara bersama-sama antara variabel iklim kerja dan status gizi dengan kelelahan kerja.

Hasil uji regresi linier diperoleh nilai $\mathrm{p}=0,012$ (iklim kerja) dan $\mathrm{p}=0,040$ (status gizi). Nilai $\mathrm{R}=0,618$ menunjukkan bahwa kedua variabel independen memiliki hubungan yang kuat terhadap terjadinya kelelahan kerja. Berdasarkan hasil uji regresi linier diperoleh nilai $\mathrm{R}^{2}$ (koefisien determinasi) sebesar 0,381, artinya $\quad 38,10 \% \quad$ kelelahan kerja disebabkan oleh iklim kerja dan status gizi, sedangkan sisanya disebabkan oleh faktorfaktor lain. Nilai intercept (konstanta) yang diperoleh adalah $-257,200$ dan nilai B standardized coefficient (koefisien regresi) 
secara berturut-turut yaitu iklim lebih singkat, hasilnya dapat dilihat pada kerja $=0,520$ dan status gizi $=0,415$. Secara tabel 6 di bawah ini.

Tabel 6. Hasil Uji Regresi Linier

\begin{tabular}{llllll} 
Model & Value & B & $\mathbf{R}$ & $\mathbf{R}^{2}$ & Sig. Anova \\
\hline (Constant) & $-257,200$ & & & & \\
Iklim Kerja & 0,012 & 0,520 & 0,618 & 0,381 & 0,013 \\
Status Gizi & 0,040 & 0,415 & & & \\
\hline
\end{tabular}

\section{PEMBAHASAN}

\section{Analisis Hubungan Iklim Kerja dengan Kelelahan Kerja}

Iklim kerja mempengaruhi daya kerja, produktivitas, efisiensi dan efektifitas kerja seseorang. Suma'mur (1996) menjelaskan bahwa bekerja di tempat kerja dengan lingkungan kerja yang tidak nyaman (bising, panas, pencahayaan kurang, silau, banyak gas dan juga debu berhamburan) merupakan beban tambahan bagi pekerja sehingga mempercepat terjadinya kelelahan kerja. Iklim kerja yang nyaman membuat tenaga kerja tidak gerah sehingga dalam melaksanakan pekerjaannya memperoleh hasil yang baik. Suhu nyaman bagi orang Indonesia sekitar $24-26^{\circ} \mathrm{C}$. Suhu yang lebih dingin yaitu $20^{\circ} \mathrm{C}$ dapat mengurangi efisiensi kerja dengan keluhan kaku atau kurangnya koordinasi otot, sedangkan suhu panas berakibat pada menurunnya prestasi kerja dan kemampuan berfikir. Hal ini akan semakin buruk apabila suhu mencapai $32^{\circ} \mathrm{C}$. Santoso dalam Amalia (2013 mengatakan bahwa lingkungan kerja yang panas dan lembab akan menurunkan produktivitas dan kesehatan kerja sehingga diperlukan suhu yang nyaman untuk penyesuaian waktu kerja dan perlindungan yang tepat untuk tenaga kerja.

Hendra (2009) mengatakan bahwa suhu lingkungan kerja yang ekstrem menyebabkan seseorang tidak nyaman berada di tempat tersebut. Suhu lingkungan yang panas akan menyebabkan cepat lelah, mengantuk, berkurangnya penampilan kerja, dan meningkatkan kesalahan kerja. Menurut Tarwaka (2004) pemaparan suhu lingkungan panas yang berlebihan dapat menyebabkan gangguan perilaku dan penampilan kerja seperti kelelahan.

Pengukuran iklim kerja di ballast tank bagian reparasi kapal PT. X dilakukan di enam titik dengan masing-masing pengukuran satu kali setiap titik. Pengukuran dilakukan di enam kapal yang sedang direparasi dengan jenis yang 
berbeda, yaitu KT Minas/P.35, Kapal Tongkang Rimau 3002, KT Menggala, KT Kamojang, KM. Srimau, dan KRI. Lambung Mangkurat-372. Hasil dari pengukuran diperoleh bahwa ISBB terendah yaitu $33,36^{\circ} \mathrm{C}$ dan ISBB tertinggi yaitu $34,83^{\circ} \mathrm{C}$. Menurut Permenakertrans Nomor PER-13/MEN/X/2011 Nilai Ambang Batas (NAB) Iklim Kerja Indeks Suhu Basah dan Bola (ISBB), pekerja dengan pengaturan waktu kerja setiap jam $50-75 \%$ dengan beban kerja ringan diperkenankan bekerja pada lingkungan dengan ISBB $30,6^{\circ} \mathrm{C}$. Pekerja dengan beban kerja sedang diperkenankan bekerja pada lingkungan dengan ISBB $29,0^{\circ} \mathrm{C}$ dan pekerja dengan beban kerja berat diperkenankan bekerja pada lingkungan dengan ISBB $27,5^{\circ} \mathrm{C}$. Dilihat dari hasil pengukuran tersebut, menurut Kepmenaker Nomor 51 tahun 1999 iklim kerja di ballast tank melebihi NAB. Hal ini menunjukkan bahwa iklim kerja dengan suhu yang tinggi dapat memicu terjadinya kelelahan, sebab suplai oksigen yang dibutuhkan oleh tubuh berkurang. Hal ini juga sejalan dengan Suma'mur (2009) yang menyatakan bahwa suhu $>32^{\circ} \mathrm{C}$ akan menurunkan kemampuan berpikir, mengurangi kelincahan, memperpanjang waktu reaksi dan memperlambat waktu pengambilan keputusan, mengganggu kecermatan otak, mengganggu koordinasi saraf perasa dan motoris, serta meningkatkan emosi.
21 responden yang bekerja di ballast tank dengan lingkungan panas melebihi NAB, 100\% mengalami kelelahan. Hasil ini didapat dari pengukuran kelelahan dengan menggunakan metode KAUPK2 dalam bentuk kuesioner yang dibagikan dan diisi oleh responden. Kelelahan yang dirasakan oleh 21 responden ini berbedabeda dikarenakan pada saat penelitian ini dilakukan, pekerjaan yang dilakukan oleh tenaga kerja berbeda - beda. Beberapa tenaga kerja bekerja di dalam ballast tank dengan kegiatan menguras air, menyekop lumpur dan membersihkan kerak - kerak yang menempel di dinding ballast tank dan mengangkat kotoran ke atas. Sebagian pekerja bekerja di luar ballast tank menarik kotoran yang telah dibersihkan oleh pekerja yang ada di dalam ballast tank untuk dibuang.

Hasil analisis hubungan iklim kerjadan kelelahan didapatkan hasil bahwa nilai koefisien korelasi sebesar 0,461 artinya keeratan hubungan antara iklim kerja dan kelelahan kerja sedang dan searah. Searah yang dimaksud adalah, apabila iklim kerja naik maka kelelahan kerja yang terjadi juga akan meningkat. Hasil perhitungan diperoleh bahwa paling banyak pekerja mengalami kelelahan sedang yaitu $10 \quad(47,6 \%)$ responden. Responden yang mengalami kelelahan ringan sebanyak $5(23,8 \%)$ orang dan yang 
mengalami kelelahan berat sebanyak 6 $(28,6 \%)$ orang.

Suhu panas yang menyebabkan kelelahan kerja pada pekerja di ballast tank ini disebabkan oleh konstruksi ballast tank sendiri yang terbuat dari baja yang mudah menyerap panas, selain itu kapal berada pada area dokking outdoor dan di pinggir laut. Paparan panas yang terus-menerus dapat memicu terjadinya kelelahan kerja Ardyanto (2005) berpendapat bahwa dengan pengadaan ventilasi umum diharapkan panas yang menyebar secara radiasi, konduksi, dan konveksi ke seluruh ruang kerja dapat mengalir ke luar dimana suhu udaranya lebih rendah. Hal ini tidak mungkin dilakukan karena akan merubah konstruksi kapal dan sulit untuk dilakukan. Pemasangan blower oleh pihak perusahaan di area kerja pekerja sebaiknya dilakukan dengan tujuan mengalirkan panas yang ada di ballast tank ke tempat yang suhu udaranya lebih rendah. Selain itu dengan beban kerja yang dimiliki dan nilai ISBB yang tinggi di area kerja sebaiknya pihak perusahaan memberikan waktu istirahat ekstra dan memberikan tempat istirahat yang sejuk untuk mengurangi paparan iklim kerja yang melebihi NAB. Hal itu bisa dilakukan dengan memberikan waktu itirahat 30 menit setelah 1,5-2 jam bekerja seperti yang sudah dilakukan oleh pekerja meskipun tidak ada aturan yang menyebutkan seperti itu.

\section{Analisis Hubungan status Gizi dengan Kelelahan Kerja}

Pemberian gizi pada tenaga kerja bertujuan untuk meningkatkan derajat kesehatan, efisiensi, produktivitas yang tinggi, mempertahankan dan meningkatkan ketahanan tubuh serta menyeimbangkan kebutuhan gizi dan kalori terhadap pekerjaan yang dilakukan. Hasil penelitian menurut status gizi responden diketahui bahwa responden paling banyak berstatus gizi normal. Dari 21 tenaga kerja yang diukur status gizi dan kelelahannya didapatkan sebanyak 2 orang dengan status gizi kurus mengalami kelelahan sangat lelah. Tenaga kerja dengan status gizi normal merasakan kurang lelah sebanyak 7 orang dan sebagian besar tenaga kerja dengan status gizi gemuk mengalami kelelahan sangat lelah sebanyak 6 orang.

Hasil dari uji korelasi didapatkan nilai koefisien korelasi sebesar 0,341. Nilai tersebut menunjukkan adanya hubungan yang lemah antara status gizi dengan kelelahan kerja. Hubungan tersebut disebabkan sebagian besar pekerja dengan status gizi kurus dan gemuk mengalami kelelahan tingkat berat. Menurut Suma'mur (1996) bahwasannya bila status gizi dikaitkan dengan kelelahan kerja, maka seseorang dengan status gizi kurus atau berat badan kurang cenderung lebih mudah mengalami kelelahan karena keterbatasan atau ketidaksediaan cadangan 
zat gizi yang nantinya diubah menjadi energi saat beraktifitas. Tidak berbeda dengan seseorang yang memiliki status gizi gemuk, mereka juga cepat mengalami kelelahan karena selain memiliki keterbatasan kemampuan otot dan tulang juga disebabkan adanya timbunan lemak pada alat vital yang ada di dalam tubuh sehingga mengalami hambatan dalam melaksanakan fungsinya.

Sependapat dengan Supariassa dkk (2006) bahwa masalah gizi tidak normal (kelebihan atau kekurangan) pada usia dewasa yaitu 18 tahun ke atas merupakan suatu masalah penting yang dapat menunjang pekerjaan dan harus diperhatikan. Hal tersebut dikarenakan adanya risiko penyakit-penyakit tertentu yang akan timbul dan menyebabkan seseorang cepat mengalami kelelahan serta akan mempengaruhi produktivitas kerja. Tarwaka (2004) berpendapat bahwa status gizi merupakan penyebab terjadinya kelelahan kerja yang diperkuat dengan hasil riset yang dilakukan oleh Oentoro (2004) bahwa secara klinis status gizi seseorang dengan performa tubuh mempunyai hubungan. Seseorang dengan kondisi gizi yang kurang baik dalam arti asupan makanan yang ada di dalam tubuh kurang dari normal maka akan lebih mudah mengalami kelelahan dalam melakukan pekerjaan.
Pihak perusahaan tidak menyediakan jatah makan dalam bentuk makanan, namun diberikan dalam bentuk uang. Hal ini bisa menyebabkan asupan gizi pekerja tidak sesuai dengan beban kerja karena belum tentu pekerja bisa menyesuaikan gizi kerja. Seharusnya pekerja menyesuaikan asupan gizi yang dibutuhkan dengan beban kerja yang dimiliknya. Ketidaksesuaian asupan gizi akan membuat pekerja lebih cepat merasakan kelelahan kerja daripada pekerja dengan asupan gizi yang normal. Hasil penelitian Ardianita menyatakan bahwa kelelahan sangat tinggi dialami oleh responden dengan status gizi gemuk, yaitu sebanyak $8(42,1 \%)$ orang dari total sampel. Pihak perusahaan harusnya memperhatikan faktor status gizi pekerja untuk menghindari terjadinya kelelahan kerja.

\section{Analisis Hubungan Iklim Kerja dan status Gizi dengan Kelelahan Kerja}

Hasil yang didapat menunjukkan bahwa iklim kerja dan status gizi berpengaruh terhadap terjadinya kelelahan kerja. Sumbangan efektif total yang diberikan oleh dua faktor tersebut adalah sebesar 0,381. Kedua faktor tersebut, yaitu iklim kerja dan status gizi jika berkombinasi maka akan lebih berpotensi menyebabkan kelelahan kerja. Sejalan dengan penelitian Anonim dalam 
Setyawati (2010) yang menyebutkan bahwa penyebab kelelahan kerja berasal dari faktor psikis, fisik, dan kombinasi dari faktor fisik dan non fisik.

Secara bersama-sama iklim kerja dan status gizi akan berpengaruh terhadap terjadinya kelelahan kerja sebesar 38,10\% dan sisanya disebabkan oleh faktor-faktor lainnya. Seperti yang sudah dipaparkan sebelumnya bahwa kelelahan kerja mempunyai banyak faktor penyebab. Faktor lain yang mungkin berhubungan yaitu beban kerja, jenis kelamin, dan tingkat pendidikan. Hasil uji juga didapatkan bahwa faktor iklim kerja adalah faktor yang paling berpengaruh terhadap terjadinya kelelahan kerja dengan nilai $\mathrm{B}=0,520$. Hal ini dikarenakan pada saat bekerja, hasil pengukuran iklim kerja di area kerja semuanya melebihi NAB.

Pekerjaan yang dilakukan di area dengan iklim kerja yang melebihi NAB tentu akan membuat pekerja lebih cepat mengalami kelelahan kerja. Kelelahan kerja yang dialami juga tidak hanya berasal dari faktor fisik lingkungan kerja saja, namun juga berasal dari faktor non fisik. Faktor non fisik ini bisa berasal dari faktor individu seperti status gizi. Asupan gizi yang tidak sesuai, seperti halnya pada penelitian ini bahwa pekerja tidak mendapatkan gizi kerja sesuai rekomendasi karena jatah diberikan dalam bentuk uang makan akan memicu terjadinya kelelahan kerja. Akumulasi kelelahan kerja yang terjadi pada pekerja akan memberikan dampak buruk. Pendapat Gilmer dalam Setyawati (2010) menyebutkan bahwa klelahan kerja dapat menimbulkan beberapa keadaan seperti: prestasi kerja menurun; fungsi motorik dan neural yang menurun; badan terasa tidak enak; semangat kerja menurun; meningkatkan terjadinya kecelakaan kerja; dan penurunan produktivitas kerja, maka dari itu pihak perusahaan harus memperhatikan kedua faktor tersebut agar tidak terjadi kelelahan kerja yang akan berdampak buruk.

\section{SIMPULAN}

Seluruh responden berjenis kelamin laki-laki. Usia responden terbanyak berkisar antara 36-50 tahun dengan frekuensi 13 orang. Masa kerja paling banyak yaitu berkisar antara 16-25 tahun sebanyak 15 responden. Pendidikan terbanyak yaitu SMA/SMK sebanyak 20 responden, hampir keseluruhan.

Nilai ISBB di ballast tank menunjukkan hasil melebihi NAB iklim kerja yang diperkenankan.

Status gizi tenaga kerja yang bekerja di ballast tank PT. X Surabya terbanyak adalah dalam kategori normal.

Kategori kelelahan kerja paling banyak dirasakan responden adalah sangat lelah. 
Iklim kerja dan kelelahan kerja memiliki kuat hubungan sedang dan arah hubungan positif yang menunjukkan bahwa semakin tinggi iklim kerja maka semakin tinggi tingkat kelelahan yang dialami.

Status gizi dan kelelahan kerja memiliki kuat hubungan rendah dengan arah hubungan positif.

Iklim kerja dan status gizi secara bersama-sama memiliki pengaruh yang kuat terhadap terjadinya kelelahan sebesar 38,10\%. Iklim kerja merupakan faktor yang paling berpengaruh terhadap kelelahan dibandingkan status gizi.

\section{SARAN}

Pemasangan atau instalasi blower pada area kerja saat pekerja melakukan aktivitas pekerjaan, hal ini dimaksudkan untuk mengalirkan panas yang ada di dalam ballast tank ke tempat yang suhunya lebih rendah sehingga suhu di dalam ballast tank diharapkan lebih rendah.

Pemberian waktu istirahat ekstra di sela-sela aktivitas pekerjaan. Hal ini bisa dilakukan misalnya dengan memberikan waktu istirahat ekstra 30 menit setelah 1,5-2 jam bekerja, selain itu juga memberikan tempat istirahat yang udaranya sejuk.
Pemantauan status gizi pekerja dengan cara pengukuran tinggi badan dan penimbangan berat badan yang selanjutnya hasil pemantauan akan diinfokan kepada pekerja. Selain itu perlu dilakukan sosialisasi kepada pekerja dengan media leaflet atau dalam bentuk buku saku yang di dalamnya memuat cara menentukan status gizi, menu makan seimbang untuk pekerja, dampak status gizi terhadap kelelahan kerja, dll.

Sebaiknya perlu dilakukan pengendalian kelelahan kerja dengan mengadakan program olahraga atau kebugaran jasmani sekali dalam seminggu, selain itu juga diadakan senam ringan sebelum bekerja yang diselipkan pada saat safety briefing. Penyediaan air minum sesuai rekomendasi agar pekerja tidak mudah dehidrasi.

\section{DAFTAR PUSTAKA}

Adi, D. P. G. S., dkk. 2013. Hubungan Antara Iklim Kerja, Asupan Gizi Sebelum Bekerja, Dan Beban Kerja Terhadap Tingkat Kelelahan Pada Pekerja Shift Pagi Bagian Packing PT. $\mathrm{X}$ Kabupaten Kendal. Jurnal Kesehatan Masyarakat 2013 Volume 2 Nomor 2 April 2013. http://download.portalgaruda.org/ (sitasi 9 November 2015).

Amalia, S.F.D.A., 2013. Kelelahan Pada Tenaga Kerja Di Unit Produksi Bagian Packaging PT. X Dan Faktor yang 
Mempengaruhinya. Skripsi. Surabaya: Universitas Airlangga.

Ardhani, Z.S., 2011. Hubungan Faktor Individu Dengan Tingkat Kelelahan Kerja Subyektif Pada Tnaga Kerja Bagian Pengepakan (Flour Packing) di PT. Indofood Sukses Makmur Tbk. Bogasari Flour Mills Surabaya. Skripsi. Surabaya: Universitas Airlangga.

Ardianita, F. C., 2014. Hubungan antara Faktor Personal, Pekerjaan dan Lingkungan Kerja dengan Kelelahn Kerja subyektif (Studi di Bagian Assembly GLS (General Lighting Service) PT. Philips Indonesia). Skripsi. Surbaya: Univrsitas Airlangga.

Ardyanto, Denny., 2005. Potret Iklim Kerja dan Upaya Pengendalian Lingkungan pada Perusahaan Peleburan Baja di Sidoarjo. Journal Kesehatan Lingkungan Vol 1, No 2. Surabaya: Fakultas Kesehatan Masyarakat Universitas Airlangga.

Chesnal, Handi., 2014. Hubungan Antara Umur, Jenis Kelamin dan Status Gizi dengan Kelelahan Kerja pada Tenaga Kerja di Bagian Produksi PT. Putra Karangetang Popontolen Minahasa Selatan. Skripsi. Manado: Universitas Sam Ratulangi.

Kementerian Tenaga Kerja dan Transmigrasi., 2011. Peraturan Menteri Tenaga Kerja dan Transmigrasi Nomor PER.13/MEN/X/2011 Tahun 2011 Tentang Nilai Ambang Batas Faktor Fisika dan Faktor Kimia di Tempat Kerja. Jakarta: Bidang Ketenagakerjaan dan Ketransmigrsian Kementerian Tenaga Kerja dan Transmigrasi.

Lemenshow, S., dkk., 1997. Besar Sampel dalam Penelitian Kesehatan (terjemahan). Yogyakarta: Gadjahmada University Press.
Nurmianto, E., 2004. Ergonomi Konsep Dasar dan Aplikasinya. Surabaya: Guna Widya.

Oentoro, S., 2004. Kampanye Atasi Kelelahan Mental dan Fisik. Jakarta: Universitas Indonesia Press.

Priyono, D., 2010. Iklim Kerja dan Kelelahan Subyektif Pada Pekerja Proyek Relokasi Jalan Arteri Raya Porong-Siring 1 Paket Sidoarjo. Skripsi. Surabaya: Universitas Airlangga.

Setyawati, L. M.., 2010. Selintas Tentang Kelelahan Kerja. Yogyakarta: Amara Books.

Setyawati, N., 2013 Analisis Kelelahan Kerja Berdasarkan Beban Kerja Pada Tenaga Kerja Bagian Produksi Y, PT X Surabaya. Surabaya: Universitas Airlangga.

Suma'mur, P. K., 1996. Hygiene Perusahaan dan Keselamatan Kerja. Cetakan Kedua. Jakarta: CV. Haji Mas Agung.

Suma'mur, P.K., 2009. Higene Perusahaan Dan Kesehatan Kerja (Hiperkes). Jakarta: Sagung Seto.

Supariasa, dkk., 2013. Penilaian Status Gizi. Jakarta: Penerbit Buku Kedokteran EGC.

Susetyo, J., 2012. Pengaruh Shift Kerja Terhadap Kelelahan Karyawan Dengan Metode Bourden Wiersman Dan 30 Item of Rating Scale. Jurnal Teknologi Volume 5 Nomor 1. (Online) http://jurtek.akprind.ac.id/ (sitasi 9 November 2015)

Tarwaka, dkk., 2004. Ergonomi untuk Keselamatan, Kesehatan Kerja dan Produktivitas. Edisi 1. Surakarta: Uniba Press. 
Tarwaka. 2008. Keselamatan dan

Kesehatan Kerja Manajemen dan

Implementasi K3 di Tempat Kerja.

Surakarta: Harapan Press.

Tarwaka., 2010. Ergonomi Industri:

Dasar-Dasar Pengetahuan Ergonomi

dan Aplikasi di Tempat Kerja.

Surakarta: Uniba Press.

Hendra., 2009. Tekanan Panas dan

Pengukuran di tempat kerja. Jakarta:

Universitas Indonesia. 